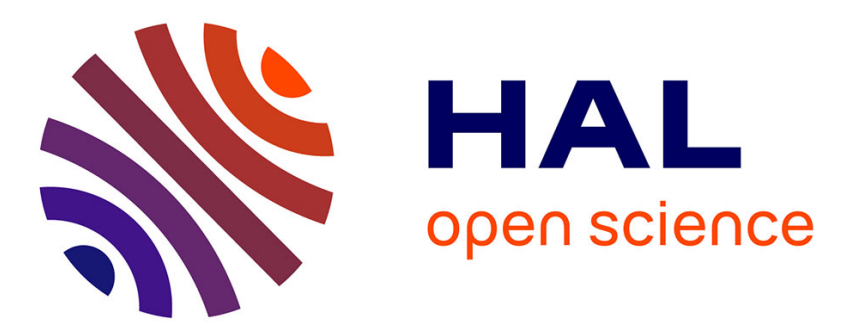

\title{
The Need of Performance Indicators for Collaborative Business Ecosystems
}

\author{
Paula Graça, Luis M. Camarinha-Matos
}

\section{To cite this version:}

Paula Graça, Luis M. Camarinha-Matos. The Need of Performance Indicators for Collaborative Business Ecosystems. 6th Doctoral Conference on Computing, Electrical and Industrial Systems (DoCEIS), Apr 2015, Costa de Caparica, Portugal. pp.22-30, 10.1007/978-3-319-16766-4_3 . hal01343461

\section{HAL Id: hal-01343461 \\ https://hal.inria.fr/hal-01343461}

Submitted on 8 Jul 2016

HAL is a multi-disciplinary open access archive for the deposit and dissemination of scientific research documents, whether they are published or not. The documents may come from teaching and research institutions in France or abroad, or from public or private research centers.
L'archive ouverte pluridisciplinaire HAL, est destinée au dépôt et à la diffusion de documents scientifiques de niveau recherche, publiés ou non, émanant des établissements d'enseignement et de recherche français ou étrangers, des laboratoires publics ou privés. 


\title{
The Need of Performance Indicators for Collaborative Business Ecosystems
}

\author{
Paula Graça ${ }^{1}$ and Luís M. Camarinha-Matos ${ }^{1,2}$ \\ ${ }^{1}$ Centre for Technologies and Systems (CTS) - UNINOVA \\ ${ }^{2}$ Faculty of Sciences and Technology, Universidade Nova de Lisboa \\ Campus de Caparica, 2829-516 Caparica, Portugal \\ mgraca@deetc.isel.ipl.pt, cam@uninova.pt
}

\begin{abstract}
During last decades there has been a trend to build collaboration platforms as enablers for groups of enterprises to jointly provide integrated services and products. As a result, the notion of business ecosystem is getting wider acceptance. However, a critical issue that is still open, despite some efforts in this area, is the identification of adequate performance indicators to measure and motivate sustainable collaboration. This work-in-progress addresses this concern, briefly presenting the state of the art of relevant contributing areas such as, collaborative networks, business ecosystems, enterprise performance indicators, social networks analysis, and supply chains. Complementarily, through an assessment of current gaps, the research challenges are identified and an approach for further development is proposed.
\end{abstract}

Keywords: Collaborative Network, Digital Ecosystem, Business Ecosystem, Digital Business Ecosystem, Performance Indicators.

\section{Introduction}

The concept of Business Ecosystem was introduced by Moore in the 1990s [1], using natural ecosystems as a biological metaphor to explain a business environment. The author considers a business ecosystem "an economic community supported by a foundation of interacting organizations and individuals - the organisms of the business world. This economic community produces goods and services of value to customers, who themselves are members of the ecosystem". Furthermore, he highlights the interdependence between all the actors of the ecosystem, who "coevolve their capabilities and roles" [2].

This concept has been refined in the last two decades, namely as a result of the enabling role of ICT. One example is the emergence of the term Digital Business Ecosystem (DBE) [3], which puts a stronger emphasis on the technological support perspective. The DBE concept was primarily introduced as a policy strategy to address the challenge of achieving for every industry, sector and region, an effective adoption of ICT, namely enabling SMEs to become more innovative and competitive in global markets [4]. As such, it can be considered as a natural evolution of the business environment, from the e-mail and web-sites, to e-commerce and collaborative e-business. The DBE notion follows Moore's inspiration in natural ecosystems, but expressed it in terms of a "digital environment" populated by "digital 
species" which could be software components, applications, services, knowledge, business models, training modules, contractual frameworks, laws, etc. These "digital species", like the living species, interact, express an independent behavior, end evolve - or becomes extinct - following the laws of market selection [3].

On the other hand, the emergence of the discipline of Collaborative Networks [5] which has a wider scope, allowed to classify business ecosystems as a sub-class of a virtual organization breeding environment (VBE), which acts as a source network of organizations, providing an adequate collaborative environment (common business processes, interoperable infrastructures, mutual trust, among others) [6]. To answer to nowadays demanding market challenges, organizations must collaborate to overcome their weaknesses and strengthen their expertise, to offer better integrated services and gain competitive advantage. In order to emphasize this perspective, the term Collaborative Business Ecosystem can be adopted.

However, in spite of the potential benefits of collaboration, many networks face difficulties as it is not always obvious to each of its members what they can benefit. Unlike the case of individual enterprises management, for which there are wellknown indicators and balanced scorecards [7], for enterprise networks in general, and even for business ecosystems in particular, there is still a lack of well identified and widely accepted performance indicators to measure collaborative benefits, motivating sustainability, and ensuring ecosystem's resiliency. This work is motivated by this need, and is led by the following research question:

What can be a suitable approach to assess collaboration performance and promote collaboration sustainability in collaborative business ecosystems?

For a better understanding of the proposed research contributing, this main research question is further divided into two sub-questions: What is a reasonable set of key performance indicators to measure and assess collaboration benefits in a collaborative business ecosystem? How to promote collaboration sustainability and resilience within a business ecosystem?

In order to find an answer for these questions, our research is guided by the following corresponding hypotheses: (H1) Collaboration benefits can be evaluated and made explicit if a set of indicators is established through a holistic combination of concepts on value and benefit derived from a number of research areas such as value systems, social networks analysis, supply chain performance, and theories of complexity. (H2) Sustainability and resilience of collaboration in business ecosystems can be promoted if a system of incentives, combined with transparent assessment methods, is implemented at the ecosystem level. In this context, this work corresponds to only the first stage, where the state of the art of the most relevant contributing research areas is analyzed, main gaps are identified, and promising directions to overcome these gaps are proposed.

\section{Relationship to Cloud-based Engineering Systems}

Nowadays cloud computing is changing the way the organizations manage their ICT resources and expertise. Cloud servers, cloud storage, and more generically cloud platforms offer to enterprises, more economic, scalable, and secure infrastructures for them to manage their business. This trend is contributing to boost emergent 
collaborative platforms operating in the cloud and offering network infrastructures and tools to logically connect individual organizations, under a common collaboration context. Such context is defined as a set of services under a coordinated choreography on contributing for some valuable objective, allowing interoperability between people or systems that can work together for some business goals [8]. These generic collaboration spaces support virtual organizations and virtual organizations breeding environments, being particularly promising for SME networks [9]. Complementarily, the developments on Internet of Things, facilitating access to a large number of information sources, enable the materialization of the concept of sensing enterprise and the effective implementation of better performance measurement mechanisms.

\section{Brief Survey of the State of the Art}

Our attempt to establish performance indicators for collaborative business ecosystems considers input knowledge from a number of research areas such as collaborative networks, business ecosystems, enterprise performance indicators, social networks analysis, and supply chain. An overview of these areas is presented below, briefly characterizing them and highlighting important aspects for the proposed work:

Collaborative Networks (CNs), one of the main contributing scientific disciplines on which this research work is based. A $\mathrm{CN}$ is defined as "a network consisting of a variety of entities (e. g. organizations and people) that are largely autonomous, geographically distributed, and heterogeneous in terms of their operating environment, culture, social capital and goals, but that collaborate to better achieve common or compatible goals, and whose interactions are supported by computer networks" [5], [6]. Important foundations for this area were earlier established by projects such as THINKcreative, VOmap, VOSTER, ECOLEAD, and many others. A large diversity of collaborative networks can nowadays be identified on a variety of sectors in industry and services. In order to better understand this diversity, some efforts focused on the establishment of reference models, such as ARCON [6]. According to ARCON, collaborative networks are divided into two main groups, the organized collaboration and the ad-hoc collaboration. The organized collaborative networks are in turn divided into long-term strategic networks and goaloriented networks, where participants are linked together to drive a continuous specific activity, or to grab a business opportunity. Under this classification, a Business Ecosystem is seen as a sub-class of long-term strategic networks. Supply chains are considered as a particular case of goal-oriented networks. In fact, traditional supply chains tend to evolve to more collaborative structures, leading to the concept of Supply Chain Collaboration (SCC). A SCC can be defined "as a longterm partnership process where supply chain partners with common goals work closely together to achieve mutual advantages that are greater than the firms would achieve individually" [10].

While most works on collaborative networks have mainly addressed issues of collaboration support infrastructures and tools, organizational and governance models, very few references can be found on performance measurement in enterprise networks. The exception is perhaps the case of supply chains for which some works can be found. For instance, [11] identifies different levels or intensity in the 
collaboration, which are categorized into two types of collaborative practices. The first one considers the exchange of information as the most basic form of collaboration, distinguishing two broad groups depending on the closeness, information exchange or process integration, also called structural collaboration [12]. The second one considers three gradual organizational and decision-making levels (operational, tactical and strategic), i.e. the higher the degree of partners' relationships towards process integration, the stronger the interaction, sophisticated information technology, and organizational commitment among them.

Business Ecosystems. Since the introduction of the Business Ecosystem concept by Moore [1], [2], several other researchers have focused on the ICT support to this organizational structure, as illustrated by the notion of Digital Business Ecosystem [3][4]. Various authors have explored analogies between natural ecosystems and mechanisms provided by computational models such as service-orientation, multiagent systems, and swarm intelligence. Two examples can be found in [13], [14]. These authors worked towards the establishment of the basis of a digital ecosystem, considering it as a collaborative environment, where the key elements are the "species" and the environment comprising support technologies and services. The species are "biological - humans", "economic - organizations", and "digital computers, software, applications,..." linked by networks and interacting with each other to achieve benefits and objectives. Another example is given by the work of Briscoe [15], [16], which uses modeling techniques from complex adaptive systems and multi-agent systems to create a generic definition inspired by biological ecosystems, which abstractly defines the key properties, behavior, and structure of an ecosystem. The emphasis in this line of research has been, so far, more oriented to the structure, organization, behavior, and technological support of the ecosystem. Therefore, and to the best of our knowledge, the aspects of performance of such systems remain an open issue.

Performance Indicators (PI) are financial and non-financial metrics used to quantify objectives and reflect strategic performance of an organization. This kind of metrics has been largely developed for individual enterprises management but not so much to assess collaborative strategy and benefits. Nevertheless, some research lines have generated a number of elements that can be taken as a basis for the development of performance indicators tailored to collaborative networks. One of these lines has pursued the identification and characterization of collaboration benefits and value systems. Another relevant line is the social networks analysis, which has established several metrics related to graph structures. In summary:

Collaboration Benefits. A number of works have tried to model (business) benefits resulting from collaboration. One example is an estimation model for business benefits in horizontal collaborative networks for product development [17], which considers four phases: 1) Estimation of the opportunities that should be generated by the network; 2) Construction of the product realization graph giving a weight to each opportunity, 3) Identification of the best consortium to develop the product, and 4) Summation of the earnings. Another work [18] suggests a set of collaboration benefits through the identification of cooperation variables and respective target goals. In this work it is argued that the perception of collaboration benefits are related to the two strategic goals perspectives - performance increase and survival capacity. Our research question is somehow in line with this perception. Although these early works 
have contributed to a better understanding of collaboration benefits, the proposed indicators have not been specifically tailored to collaborative business ecosystems. Furthermore, validation of these indicators in terms of their contribution to promote collaboration sustainability and resilience has not been extensively done yet.

Value Systems. Progress has been made in terms of conceptualization of value systems for collaborative networks, namely through combining views coming from the social sciences and the economy. One example is a conceptual model for value systems for collaborative networks [19], based on the identification of objects that can be evaluated, and the elements that represent the mechanisms of evaluation. More recent developments of this work [20] suggest methods to assess the alignment of value systems of different members of a network. The proposed system remains, however, quite limited when it comes to the evaluation mechanisms. Another proposal for a conceptual model, formalizes a value system for a VBE [21], and a corresponding performance measurement system. This system intends to evaluate the value co-creation process through a set of indicators that quantify the VBE results, making easier to monitor its progress. The authors also propose the balanced scorecards (BSC) to monitor the performance measurement. A BSC is a classical method [7] composed of a set of performance indicators strongly aligned with the vision and strategy of the enterprise, and which represents an innovation compared to other types of metrics existing at the time focused only on financial indicators, by the combination of lagging and leading indicators, resulting not only in historical indicators, but also in predictable results. These proposals, e.g. [21], remain, however, at a general conceptual level, without providing concrete indicators.

Social Network Analysis. The large adherence of people to social networks has motivated a substantial amount of research, often under the umbrella of Social Network Analysis (SNA). A number of research works have also attempted to borrow methods and indicators from SNA to apply in collaborative networks. But there are also a number of arguments pointing to the limitations of SNA when adopted for the analysis of business networks, namely: i) the empirical link between organizationallevel structure and firm-level performance is not adequately demonstrated; ii) links in a social network allow a structural analysis, such as degrees of separation between nodes, "betweenness", "closeness", among others, but do not address economic or social value creation; iii) all links in a social network are of the same nature and only one link is represented between actors, not allowing, for instance, to distinguish social or economic exchanges; and iv) to analyze and interpret the network patterns requires high level of expertise. An attempt to overcome these limitations is the work of Allee [22], which introduces the concept of Value Network Analysis (VNA). A VNA is defined as "any purposeful group of people or organizations creating social and economic good through complex dynamic exchanges of tangible and intangible value" [22]. According to the author, a value network is a "human-centric, role-based, network view of any business activity". A set of metrics for managing collaborative work have been proposed in this context, representing a promising direction.

\section{Research Approach}

The analysis of the literature, as briefly shown above, shows that an adequate 
approach to measure and manage performance in collaborative business ecosystems is not available yet. However, several partial and, to some extent, complementary contributions can be found in a number of research fields. Bringing together all these contributions, can provide a promising direction towards identifying suitable performance indicators that not only help in performance measurement, but also contribute to the promotion of collaboration sustainability and resilience. As a result, our research approach is driven by 3 main pillars as illustrated in Fig. 1: (1) An organizational and collaborative framework, to provide an understanding of the structure, organization and behavioral aspects of the collaborative business ecosystem; (2) Performance indicators and mechanisms, to allow quantitative assessment of performance and potential benefits for the ecosystem members and the ecosystem as a whole; (3) A set of enablers, mainly provided by ICT infrastructures and new computational models that inspire and support various alternatives of organizational structures and simulation models.

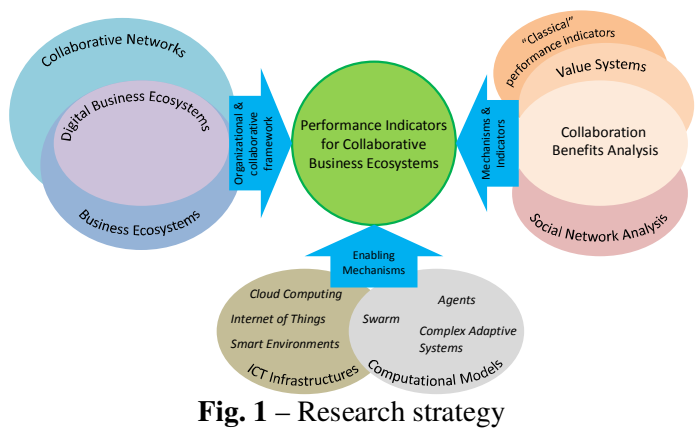

The initial phase of the work allowed identifying the potential contributions from each of the mentioned areas and putting them into a context. One difficulty with establishing performance indicators is that their actual value depends, to a large extent, on their acceptance by the involved community. Therefore, it is not strictly and issue of "proving" their validity in classical research terms. If a set of indicators are reasonably coherent, and based on a logical foundation, their value depends on their acceptance. As such, our approach tries to (1) guarantee the first requirements, and (2) create conditions for their acceptance.

Regarding the first aspect, at the current stage, a consolidation and formalization of concepts is being developed, together with the design of measurement mechanisms. In addition to inputs from the contributing areas mentioned above, grounded theory methods are also considered as they are likely to facilitate the capture of knowledge about the reality, behavior and interactions of the participants in a shared social context, the business ecosystem. All collected data from different formal and informal sources, allow an identification of key concepts and its categorization, leading to the establishment of collaborative performance indicators. Grounded theory emerged from the discipline of sociology, focused on society and the individual. However it has been broadening to incorporate issues with significant behavioral implications, such as ethical marketing, social marketing, green issues and experiential consumption [23], thus appearing to be also suitable for business ecosystems. A business ecosystem can be characterized by a set of key properties taken from a 
generic ecosystem inspired by biological ecosystems, combining attributes of digital, business, and social ecosystems: i) the environment is the economy of society, where agents are the businesses which influence and are influenced by the environment; ii) the population and evolution match the business domain, in which the evolutionary theory of capabilities and behavior of business firms is applicable; iii) the community matches the social domain, referring to a social unit that shares common values regardless of physical location, since, instead of being located in the same geographical region, participants are connected by a digital common infrastructure supported by ICT technologies [16].

Regarding the second aspect, we pursue the second research sub-question related to the use of the performance indicators to promote collaboration resilience and sustainability. The vision is that achieving resilience and sustainability will give a strong argument to promote wide acceptance of the proposed indicators.

At the same time, suitable validation scenarios are being analyzed. The main obstacle to the implementation of this approach is the lack of historic data or benchmarks to support effective validation. Furthermore, the main goals of using such performance indicators to promote collaboration sustainability and resilience can only be verified in the long term, a typical difficulty in most research on Collaborative Networks. Therefore, the designed validation strategy combines a mix of methods including: (partial) case studies, simulation, ethnographic methods (mainly involving business ecosystem managers), and grounded theory. Furthermore, the simulation seems to be a promising strategy, because existing specific models consistent with evolutionary theory, can be applied to business ecosystems.

\section{Conclusions and Further Work}

The analysis of the state of the art in relevant areas shows that although various relevant contributions can be found, there is still an important gap: the inexistence of adequate and effective methods for evaluation of collaboration benefits in business ecosystems. This gap points to the need of identifying suitable performance indicators and associated measurement mechanisms that can promote collaboration and cohesion of the ecosystem's members. Thus, a research strategy was designed towards developing a contribution to the survival of organizations in an aggressive and turbulent market environment. After the first stage of our work, the research framework and a preliminary solution design are achieved. The development and validation steps correspond to ongoing work. 


\section{References}

1. Moore, J. F. "Predators and prey: a new ecology of competition." Harvard business review 71, no. 3: 75-86, 1993

2. Moore, J. F. The death of competition: leadership and strategy in the age of business ecosystems. New York: HarperBusiness, 1996.

3. Nachira, F. . Towards a network of digital business ecosystems fostering the local development. Technical report, DG Information Society and Media, EC, 2002

4. Nachira, F., P. Dini, and A. Nicolai. A network of digital business ecosystems for Europe: roots, processes and perspectives. European Commission, Introductory Paper, 2007

5. Camarinha-Matos, L. M., and H. Afsarmanesh. Collaborative networks: A new scientific discipline. J. Intelligent Manufacturing, vol. 16, $\mathrm{N}^{\circ} 4-5$, pp439-452, 2005

6. Camarinha-Matos, L. M., and H. Afsarmanesh. Collaborative Networks: Reference Modeling: Reference Modeling. Springer, 2008

7. Kaplan, R. S., and D. P. Norton. The balanced scorecard: translating strategy into action. Harvard Business Press, 1996

8. Osório, A. L., L. M. Camarinha-Matos, and H. Afsarmanesh. "Cooperation Enabled Systems for Collaborative Networks." In Adaptation and Value Creating Collaborative Networks, pp. 400-409. Springer Berlin Heidelberg, 2011

9. Osório, A. L., L. M. Camarinha-Matos, and H. Afsarmanesh. "Enterprise Collaboration Network for Transport and Logistics Services." In Collaborative Systems for Reindustrialization, pp. 267-278. Springer Berlin Heidelberg, 2013

10. Cao, M., M. A. Vonderembse, Q. Zhang, and T. S. Ragu-Nathan. "Supply chain collaboration: conceptualisation and instrument development." International Journal of Production Research 48, no. 22: 6613-6635, 2010

11. Botta-Genoulaz, V., J.-P. Campagne, D. Llerena, and C. Pellegrin, eds. Supply Chain Performance: Collaboration, Alignment, and Coordination. John Wiley \& Sons, 2013

12. Vereecke, A., and S. Muylle. "Performance improvement through supply chain collaboration in Europe", IJ Operations \& Production Manag. 26(11): 1176-1198, 2006

13. Chang, E., and M. West. "Digital Ecosystems A Next Generation of the Collaborative Environment." In iiWAS, pp. 3-24, 2006

14. Boley, H., Chang, E., "Digital Ecosystems: Principles and Semantics," Digital EcoSystems and Technologies Conference, 2007. DEST '07. Inaugural IEEE-IES, pp.398,403, 2007.

15. Briscoe, G. "Digital ecosystems." arXiv preprint arXiv:0909.3423, 2009

16. Briscoe, G. "Complex adaptive digital ecosystems." In Proceedings of the Int. Conference on Management of Emergent Digital EcoSystems, pp. 39-46. ACM, 2010

17. Piot, G., M. Pouly, N. Cheikhrouhou, and R. Glardon. "An estimation model for business benefits in horizontal collaborative networks." In Establishing the Foundation of Collaborative Networks, pp. 345-352. Springer US, 2007

18. Abreu, A., and L. M. Camarinha-Matos. "A benefit analysis model for collaborative networks." In Collaborative networks: Reference modeling, pp. 253-276. Springer, 2008

19. Camarinha-Matos, L. M., and P. Macedo. "A conceptual model of value systems in collaborative networks." Journal of Intelligent Manufacturing 21(3) (2010): 287-299

20. Macedo, P. and L. M. Camarinha-Matos, A Qualitative Approach to Assess the Alignment of Value Systems in Collaborative Enterprises Networks, Journal Computers \& Industrial Engineering 64 (2013) 412-424

21. Romero, D., N. Galeano, and A. Molina. "A conceptual model for virtual breeding environments value systems." In: Establishing the foundation of collaborative networks, 43-52. Springer, 2007

22. Allee, V., "Value Networks and the true nature of collaboration." Digitial edition edn. ValueNet Works and Verna Allee Associates, 2011

23. Goulding, C. "Grounded theory, ethnography and phenomenology: A comparative analysis of three qualitative strategies for marketing research." European Journal of Marketing 39, no. 3/4: 294-308, 2005. 